\title{
Prediksi Jumlah Penumpang Kapal Laut di Pelabuhan Laut Manado Menggunakan Model ARMA
}

\author{
Jeine Tando ${ }^{1}$, Hanny Komalig ${ }^{2}$, Nelson Nainggolan ${ }^{3 *}$ \\ 1,2,3 Program Studi Matematika, Fakultas Matematika dan Ilmu Pengetahuan Alam, \\ Universitas Sam Ratulangi Manado \\ *corresponding author email: n-nelson@ unsrat.ac.id
}

\begin{abstract}
Abstrak
Tujuan penelitian ini adalah menentukan model ARMA yang terbaik dalam memprediksi jumlah penumpang yang berangkat di pelabuhan Manado. Data yang di gunakan adalah data bulanan jumlah penumpang kapal laut dari bulan Januari 2012 sampai bulan Juni 2015. Hasil penelitian menunjukkan model ARMA $(1,2)$ menggunakan model yang lebih baik dalam meprediksi jumlah penumpang kapal laut di pelabuhan laut Manado. Prediksi untuk periode 6 bulan yakni bulan Juli 2015 sebanyak 31106 penumpang, bulan Agustus 2015 sebanyak 31406 penumpang, bulan September sebanyak 31350 penumpang, bulan oktober sebanyak 31300 penumpang, bulan November sebanyak 31256 penumpang, bulan Desember sebanyak 31217 penumpang.
\end{abstract}

Kata Kunci : Model ARMA, Time series, Prediksi.

\section{Employing ARMA Methods to Predict The Number of Ships Passanger at Manado Bay Port}

\begin{abstract}
The purpose of this study was determining the best ARMA model to predict the number of ship passenger at the Manado port. The data that, used was monthly data of ship passenger from January 2012 until June 2015. The model results showed ARMA $(1,2)$ well enought to predict the number of passenger ships in the port of manado for the 6 month period is July 2015 as many 31106 passenger, in August 2015 as many 31406 passenger, in September 2015 as many31350 passenger, in October 2015 as many 31300 passenger, in November 2015 as many 31256 passenger, in December 2015 as many 31217 passenger.
\end{abstract}

Keywords: ARMA models, time series, prediction.

\section{Pendahuluan}

Pelabuhan laut Manado terletak di pusat kota dari Manado. Dermaganya pada umumnya dilayani oleh kapal-kapal berukuran kecil, hal ini dikarenakan lokasi perairan Manado berdekatan dengan lokasi taman laut Bunaken yang dilindungi dan perairan yang cukup dangkal.

Penelitian ini bertujuan untuk menentukan model penumpang kapal di pelabuhan laut Manado serta dapat memberikan sumbangan pemikiran khususnya pada pelabuhan kapal laut Manado, dengan memberikan perkiraan jumlah penumpang kapal laut untuk periode waktu 6 bulan, supaya pelabuhan dapat mengantisipasi fasilitas pelayanan.

\section{Material dan Metode}

Pelabuhan merupakan sebuah fasilitas di ujung samudera, sungai, atau danau untuk menerima kapal dan memindahkan barang kargo maupun penumpang ke dalamnya.

Prediksi adalah suatu proses memperkirakan secara sistematis tentang sesuatu yang paling mungkin terjadi di masa depan berdasarkan informasi masa lalu dan sekarang yang dimiliki, agar kesalahanya diperkecil.

Analisis deret waktu dikenalkan sejak tahun 1962 oleh George E. P. Box dan Gwilym M Jenkins melalui bukunya Time Series Analysis: Forecasting and Control [1]. Sejak saat itu, time 
series mulai banyak dikembangkan. Dasar pemikiran time series adalah pengamatan sekarang $\left(Z_{t}\right)$ tergantung pada satu atau beberapa pengamatan sebelumnya[2].

Suatu data pengamatan dikatakan stasioner apabila proses tidak berubah seiring dengan perubahan waktu atau dikatakan stasioner jika data tersebut mempunyai nilai mean dan variansi yang relatif konstan dari waktu ke waktu. Sebaliknya, data pengamatan yang tidak stasioner mempunyai mean dan variansi yang tidak konstan atau berubah seiring dengan berubahnya waktu[3].

Autokorelasi adalah korelasi antara suatu variabel satu atau lebih periode sebelumnya dengan dirinya sendiri. Hubungan autokorelasi dengan lag - nya dinamakan fungsi autokorelasi disingkat ACF. Fungsi autokorelasi menunjukkan keeratan hubungan antara nilai variable yang sama tetapi pada waktu yang berbeda. Rumus fungsi autokeralasi adalah sebagai berikut:

$$
\rho_{k}=\frac{\sum_{t=1}^{n-k}(x-\bar{x})\left(x_{t+k}-\bar{x}\right)}{\sum_{t=1}^{n}\left(x_{t}-\bar{x}\right)^{2}}
$$

dimana :

$\rho_{k}:$ Koefisien korelasi pada lag $-\mathrm{k}$

$\bar{x}:$ rata - rata observasi.

Autokorelasi parsial disingkat PACF digunakan untuk mengukur tingkat keeratan (association) antara $x_{t}$ dan $x_{t-k}$ apabila pengaruh dari lag $1,2,3, \ldots$, dan seterusnya sampai k- 1 dianggap terpisah. Hubungan antara autokorelasi parsial dengan lag-nya disebut fungsi autokorelasi parsial. Rumus fungsi autokorelasi parsial ditulis dengan[4] :

$$
\emptyset_{k+1, k+1}=\frac{\rho_{k+1}-\sum_{j=1}^{k-1} \emptyset_{k j} \rho_{k+1}-j}{1-\sum_{j=1}^{k-1} \emptyset_{k j} \rho_{j}}
$$

dimana $: \rho_{k}=$ nilai autokorelasi lag $-k$.

Model autoregresif disingkat AR adalah model yang menyatakan bahwa data pada periode sekarang dipengaruhi oleh data pada sebelumnya. Model autoregresif dengan orde $p$ disingkat dengan ARIMA $(p, 0,0)$. Bentuk umum dari model ini adalah sebagai berikut:

dimana :

$$
z_{t}=\mu+\emptyset_{1} Z_{t-1}+\emptyset_{2} Z_{t-2}+\cdots+\emptyset_{p} Z_{t-p}+e_{t}
$$

$$
\begin{array}{ll}
\mu & : \text { Konstanta } \\
\emptyset_{1}, \emptyset_{2}, \emptyset_{p} & \text { : koefisien parameter autoregresif ke }-p \\
Z_{t-1}, Z_{t-2,} Z_{t-p} & : \text { variabel bebas } \\
e_{t} & : \text { sisaan pada saat ke }-t
\end{array}
$$

Model moving average disingkat MA menyatakan hubungan antara nilai pengamatan dari kesalahan peramalan sekarang dan masa lalu yang berurutan, persamaan itu dinamakan moving average model. Model moving average dengan orde $q$ di singkat MA $(q)$ atau ARIMA $(0,0, q)$. Bentuk umum dari model ini adalah sebagai berikut [5]:

dimana :

$$
Z_{t}=\mu+e_{t}-\theta_{1} e_{t-1}-\theta_{2} e_{t-2}-\cdots-\theta_{p} e_{t-q}
$$

$$
\begin{array}{ll}
\mu & : \text { Konstanta } \\
\theta_{1}, \theta_{2}, \theta_{p} & : \text { Koefisien parameter moving average ke- } q \\
e_{t} & : \text { Sisaan pada saat ke- } t
\end{array}
$$

Model ARMA (Autoregressive Moving Average) adalah gabungan dari model $\operatorname{AR}(p)$ dan $\operatorname{MA}(q)$ sehingga memiliki asumsi bahwa data periode sekarang di pengaruhi oleh data periode lampauanya dan nilai lampau kesalahanya. model ARMA dengan $p$ dan $q$ ditulis $\operatorname{ARMA}(p, q)$ atau ARIMA $(p, 0, q)$. Bentuk umum dari model ini adalah sebagai berikut [5] :

$$
Z_{t}=\mu+\emptyset_{1} Z_{t-1}+\emptyset_{2} Z_{t-2}+\cdots+\emptyset_{t-p}+e_{t}-\theta_{1} e_{t-1}-\theta_{2} e_{t-2}-\cdots-\theta_{q} e_{t-q}
$$
dimana :

$$
\begin{array}{ll}
Z_{t} & : \text { Variabel tak bebas } \\
\mu: & : \text { konstanta } \\
\theta_{1}, \theta_{2}, \theta_{q} & : \text { Koefisien parameter moving average ke- } q \\
\emptyset_{1}, \emptyset_{2}, \emptyset_{p} & : \text { Koefisien parameter moving average ke- } p \\
Z_{t-1} Z_{t-2}, Z_{t-p}, & \text { Variabel bebas } \\
e_{t-q} & : \text { Sisaan pada saat ke-t- } q
\end{array}
$$


Salah satu cara yang umum dipakai dalah metode pembedaan (differencing). Proses selisih dilakukan jika data tidak stasioner dalam rata-ratanya. Metode ini dilakukan dengan cara mengurangi nilai data pada suatu periode dengan nilai data periode sebelumnya yang dapat dirumuskan sebagai berikut :

$$
W_{t}=Z_{t}-Z_{t-1}
$$

Proses ARIMA adalah model time series yang tidak stasioner. Secara umum persamaan model ARIMA adalah :

$W_{t}=\emptyset_{1} W_{t-1}+\emptyset_{2} W_{t-2}+\cdots+\emptyset_{p} W_{t-p}+e_{t}-\theta_{1} e_{t-1}-\cdots-\theta_{q} e_{t-q}$ dimana :

sehingga

$$
W_{t}=Z_{t}-Z_{t-1}
$$

$$
\begin{aligned}
& Z_{t}-Z_{t-1}= \emptyset_{1}\left(Z_{t-1}-Z_{t-2}\right)+\emptyset_{2}\left(Z_{t-2}-Z_{t-3}\right)+\cdots+ \\
& \emptyset_{p 1}\left(Z_{t-p}-Z_{t-p-1}\right)+e_{t}-\theta_{1} e_{t-1}-\cdots-\theta_{q} e_{t-q}
\end{aligned}
$$

Faktor musiman dapaat di tentukan dengan mengidentifikasi koefisien autokorelasi pada dua atau tiga time lag yang berbeda nyata dari nol.

Sebagai contoh untuk data yang dikumpulkan bulanan, pembedaan satu musiman penuh (tahun) dapat dihitung sebagai berikut :

$$
X_{t}=X_{t} \dot{-} X_{t-12}=\left(1-B^{12}\right) X_{t} .
$$

Proses pemilihan model yang tepat dilakukan dengan mengidentifikasi orde AR dan MA pada grafik ACF dan PACF. Jika autokorelasi secara eksponensial melemah menuju nol berarti terjadi proses $\operatorname{AR}(p)$. Jika autokorelasi parsial melemah secara eksponensial menuju nol berarti terjadi proses $\mathrm{MA}(q)$. Jika keduanya melemah menjadi nol maka model tersebut adalah gabungan dari AR dan MA yaitu $\operatorname{ARMA}(p, q)$.

Mean squared error (MSE) atau rata - rata kuadrat terkecil merupakan suatu kriteria dalam memilih model terbaik[2]. Semakin kecil nilai MSE yang dihasilkan suatu model maka semakin baik. Nilai MSE dapat diketahui dengan menggunakan persamaan :

dimana :

$$
M S E=\frac{1}{n} \sum_{t=1}^{n} e_{t}^{2}=\frac{\sum_{t=1}^{n}\left(Z_{t}-\hat{z}_{t}\right)^{2}}{n}
$$

$\mathrm{n}$ : banyaknya data

$Z_{t}$ : data aktual pada waktu $\mathrm{t}$

$\hat{Z}_{t}$ : data hasil prediksi pada waktu $\mathrm{t}$

\section{Metodologi Penelitian}

Penelitian ini dilakukan pada bulan Januari 2015 sampai februari 2015 di Fakultas Matematika dan Ilmu Pengetahuan Alam Universitas Sam Ratulangi Manado (FMIPA UNSRAT). Data yang digunakan pada penelitian ini adalah data sekunder yang di peroleh dari Kantor Kesyahbandaran dan Otoritas Pelabuhan Manado. Data jumlah penumpang kapal laut yang berangkat pada periode bulan januari 2012 sampai juni 2015. Melalui plot ACF (Autocorrelation Function) dan PACF (Partial Autocorrelation Function) kita dapat menentukan model ARMA yang bisa digunakan dalam prediksi. Pemilihan parameter yang tepat dilihat melalui nilai MSE (Mean Squared Error) yang paling kecil atau rata-rata kuadrat terkecil yang nilainya terkecil.

\section{Hasil dan Pembahasan}

Data jumlah penumpang kapal laut manado periode bulan Januari 2012 sampai dengan bulan Juni 2015 sebanyak 42 data. Berikut ini merupakan grafik jumlah penumpang kapal laut selama periode bulan Januari 2012 sampai Juni 2015. Berdasarkan plot pada Gambar 1 menunjukkan jumlah penumpang kapal laut Manado periode bulan Januari 2012 di mulai dari 29740 penumpang kemudian mengalami penurunan pada bulan februari dan bulan maret kemudian naik kembali pada bulan Mei menjadi 31037 penumpang terus naik pada akhir tahun 2012 yaitu pada bulan Desember sebanyak 42659 penumpang. Pada bulan Januari 2015 merupakan jumlah penumpang terbanyak yakni 59006 penumpang. 
Dari Gambar 1 juga dapat terlihat bahwa data sudah menunjukkan stasioner sehingga terhadap data ini tidak perlu dilakukan differencing. Untuk identifikasi model, dilihat melalui plot Fungsi Autokorelasi (ACF) dan Fungsi Autokorelasi Parsial (PACF). Model yang dipilih adalah yang memiliki nilai MSE (Mean Square Error) yang paling kecil. Dalam penelitian ini, model yang digunakan dengan nilai MSE yang paling kecil adalah model $\operatorname{ARIMA}(1,0,2)$ atau $\operatorname{ARMA}(1,2)$.

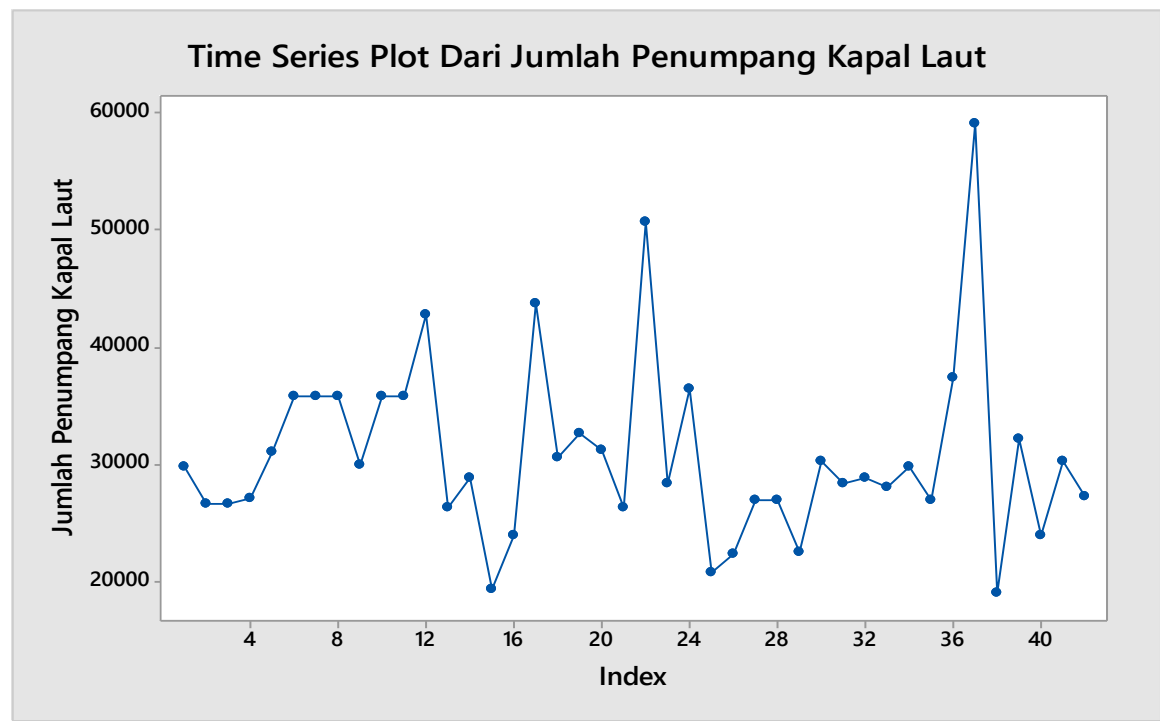

Gambar 1. Pot Data Jumlah Penumpang Kapal Laut Manado Periode Bulan Januari 2012 sampai dengan Bulan Juni 2015.

Oleh karena itu, Model $\operatorname{ARMA}(1,2)$ dalam penelitian ini adalah:

dengan $E\left(e_{t}\right)=0$, maka

$$
Z_{t}=\mu+\emptyset_{1} Z_{t-1}+e_{t}-\theta_{1} e_{t-1}-\theta_{2} e_{t-2}
$$

$$
\hat{Z}_{t}=\hat{\mu}+\emptyset_{1} Z_{t-1}-\theta_{1} e_{t-1}-\theta_{2} e_{t-2} \text {. }
$$

Penaksiran parameter menggunakan software komputer dengan koefisien AR1: 0,8798, MA1:

0,9721, MA2: 0,0978, dan konstanta 3712,10, diperoleh persamaan:

$$
\hat{Z}_{t}=3712,1+0,88 Z_{t-1}-0,97 e_{t-1}-0,09 e_{t-2} \text {. }
$$

Data Jumlah Penumpang Kapal Laut dan prediksinya bulan Januari 2012 sampai dengan bulan Juni 2015 dapat dilihat pada Gambar 2.

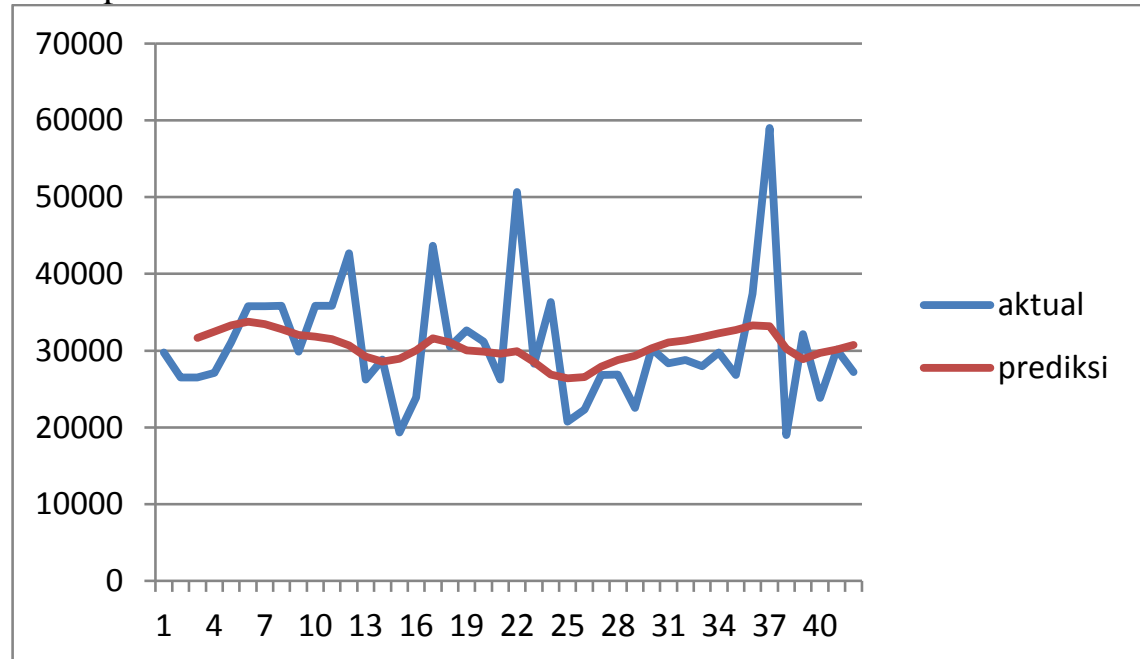

Gambar 5. Data Jumlah Penumpang Kapal Laut Dan Prediksinya Bulan Januari 2012 sampai dengan Bulan Juni 2015. 


\section{Kesimpulan}

Model time series untuk prediksi jumlah penumpang kapal laut di manado, menggunakan data periode januari 2012 sampai dengan juni 2015 diperoleh model ARMA $(1,2)$. Hasil penelitian menunjukkan prediksi jumlah penumpang kapal laut di pelabuhan laut Manado untuk periode 6 bulan berikutnya yakni bulan Juli 2015 sebanyak 31106 penumpang, bulan Agustus 2015 sebanyak 31406 penumpang, bulan September sebanyak 31350 penumpang, bulan Oktober sebanyak 31300 penumpang, bulan November sebanyak 31256 penumpang, bulan Desember sebanyak 31217 penumpang.

\section{Daftar Pustaka}

[1] Box, G.E.P, G.M, Jenkins, dan G.C, Reinsel, 1994. Time Series Analysis : Forecasting and Control Third Edition. Pearson Prentice Hall. New Jersey.

[2] Iriawan, N dan P.S. Astuti. 2006. Mengolah Data Statistik Dengan Mudah Menggunakan Minitab 14. Penerbit Andi. Yogyakarta.

[3] Nurhayati, A. 2013. Peramalan Menggunakan Model ARIMA Musiman dan Verifikasi Hasil Peramalan dengan Grafik Pengendali Moving Range (Studi Kasus: Produksi Air Bersih di PDAM Tirta Kencana Samarinda). Jurnal Eksponensial 4(1): 55-56.

[4] Wei, W. W. S. 1990. Time Series Analysis: Univariate and Multivariate Methods. AddisonWesley Publishing Company, USA.

[5] Mulyono, S. 2000. Peramalan Harga Saham dan Nilai Tukar: Teknik BoxJenkins. Ekonomi dan Keuangan Indonesia. 48(2):107 - 188. 